\title{
Do liberalismo no Brasil
}

A discussão sobre o liberalismo no Brasil em boa medida se perverteu em decorrência do emocionalismo que marcou todo o processo político-social que acabou desaguando no impeachment do presidente Fernando Collor de Mello. Até então, a discussão era relativamente fácil, embora não fosse sem custo assumir uma posição "liberal”. Depois do impeachment -e, antes dele, feita em má hora e erroneamente, a associação do programa econômico da ministra Zélia Cardoso de Mello ao liberalismo -, a simples discussão é marcada por um viés que impede se vejam as questões com clareza. A rigor, o fenômeno perverso não nasceu com a eleição de Collor de Mello; vem de antes. Só assim é que se consegue explicar porque a ira contra o liberalismo, 


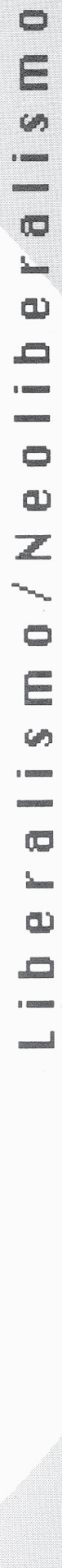

OLIVEIROS $S$.

FERREIRA é

professor-associado de Ciência Política da USP e autor de Os 45 Cavaleiros Húngaros (Editora UnB/Hucitec): 
que a rigor existia tempos atrás, mascarada, inclusive na Academia, explodiu até mesmo em círculos que apoiaram o programa escrito doantigo presidente.

Se me perguntarem se existe liberalismo no Brasil, responderei que se existem algunsque se consideram liberais, liberalismo nảo existe, porque nunca existiu. Houve liberais, uns com maior relevo na cena política, outros menos importantes. Enquanto movimentode idéias e práticas políticas, no entanto, o liberalismo nunca chegou a se estruturar (portantoa existir), em boa medida porque a realidade social militava e continua militando contra ele, seja no terreno das idéias, seja no das práticas sociais, políticas e cconômicas.

Poder-se-ia dizer, no que se refere às práticas políticas, que a afirmaçâo é por demais severa. Afinal, quem vê as constituiçôes de 1946 c 1988 não hesitarí cm dálas como liberais pela consagração dos direitos individuais c, até mesmo, da propriedade. As interpretaçóes de eminentesjuristas, dando como assente que a Carta de 88 consagra a iniciativa privada e reduzo papel do Estado na vida cconômica, abundam nostextos especializadose nasconferências sobre o problema. Se se pode contra-argumentar nesse terreno, à luz doque a Constituiçăo dispóe sobre "cartórios" económicos ou profissionais, monopólios e intervençđ̆́o estatal por motivos "estratégicos", nãocabe divergências quandose aponta a consagração dos direitos individuais, ampliados do político para o social, nisso superandodialeticamente oliberalismo, ou simplesmente o ultrapassando. Cabe ter presente, no entanto, que a Constituição escrita, a "folha de papel" a que se referia l assale, é uma coisa, a Constituição real do paísé outra. $A$ resposta à pergunta se existe liberalismono Brasil não deve ser dada tendoem vista a "folha de papel", mas as relaçöes reais de poder nasociedade e, maisque isso, o grau de consciência que a média, para nâo dizer a maioria dos cidadãos, $t \mathrm{~cm}$ dos seus direitos eda necessidade que existe de sua participaçáo na tomada de decisỏes sociais e na vida política para que se possa consolidar um Estado de Direitocm que as divergẻncias sejam aceitas, porque vistas como fato natural da vida na socicdade.

Oliberalismoé uma dróle dedoctrine, neste sentido de que é um conjunto de práticase direitos restritosaos "optimates"que nảo têm como, no plano das idéias, ncgá-las aos que a sua categoria social nảo pertencem. Ora, aquilo que não se pode negar no terrenodas idéias, mais cedoou mais tarde, será concedido no das práticas. Oliberalismo nāo cscapa dessa quase-lei. A forma pela qual se dará a ampliaçăo e passagem desses dircitos e práticas da categoria dos optimates para um número sempre maior de pessoas, que pouco a pouco adquirem a condiçăo de cidadảos, dependerá da sabe doria dosque detêm ocomandodasalavancasdopoder e da organizaçâo do movimen to dos excluídos. Se os dirigentes sio como osCapetos, que nada aprenderam nem nada esqueceram, acabam na guilhotina; se são como os ingleses, continuam no comando da sociedade, cedendolentamente, aolongodas décadas, parcelas de scusdircitosaté então usufruídos em exclusivo; se são cono osbrasileiros, depois de vencidoo Império com seus liberais c conscrvadores alternadamentebeneficiadospela Coroa, concedem tudo na Constituiçẩo, na "folha de papel", para nada ceder no terrenodaspráticase dos direitos. Os Capetostudoperderam diante do grande movimento de massas, cujo vapor Napoleão fez questão de liberar pouco a pouco durante as campanhas da "Grande Arméc"; os inglesesfo. ram cedendo igualmente diante do movimento popular e de opiniâo (a oposição extraparlamentar) que reclamava se apli. cassem as idéias que inspiravam os discursosnos Comuns. No Brasil, inexistindocssa pressão - que quando houve se manifestou diretamente como reivindicaçáosocial profunda, senáorevolucionária, levando osque professavam a doutrina liberal a formar o "partidoda Ordem" para defenderseusprivilégios supostos ameaçados -, os dirigentesdecidiram spontesta e perante oaltar de sua consciência moral (ou de sua má consciência, pouco faz) conceder direitos aos dirigidos, negando-lhes, porém, a possibilidade de aglutinar-se para fazer dessa concessâo uma realidade. Os "clubes" do Palais Royal cortaram a cabeça de L.uís XVIe de quantos eram adversários da llumanidade edas Instituiçōes, vale dizer da Revoluçio. Depois das Restauraçóes, antesde 1848, os dirigentesda T'erceira República francesa consolavam os que nảo podiam votar, nem participar da hoje chamada Cidadania, dizendo-lhes para se enriquecer. No Brasil, mandou-se cmbora o Imperador, mas houve quem conservasse os títulos nobiliárquicos, e todos os maiores de 21 anos que soubessem ler e escrever, nảo fossem 
praças de pré nem "religiosos de ordens monásticas, companhias, congregaçōes ou comunidades de qualquer denominaçăo. sujeitas a votos de obediência, regra ou estatuto, que importe a renúncia da liberdade individual", poderiam votar. Evidentemente, nos candidatos dos partidos formados pelas coteries dos dominantes. Em 1946, durante os debates na Assembléia Constituinte, pretendeu-se restabelecer a restriçăo aos "sujeitos a voto de obediência", mas nảo era mais possivel manter-se a lgreja tảo separada assim do Estado. Os analfabetos continuaram sem direito de voto até 1988 . scu númerosempre grande nocorposocial - c, mesmodepois de conquistarodireitode votar, continuaram sem conhecer seus mais elementares direitos civis como o de serem registrados pelos patrōes quando se empregam.

Contrariamente à Europa, que inspirou muitas de nossas elites, e aos Estados Unidos (que, depois de influenciarem Rui Barbosa c a Constituição de 1891, hoje atraem as classes médias e os novos-ricos que vảo a Miami c Orlando ou lá compram imóveis), os dirigentes que se consideravam liberais não cuidaram de ampliar as fran. quias sociais e políticas privativas deles $\mathrm{c}$ dos membros das diferentes coteriesem que a sociedade brasileira bem pensante se dividia c divide até hoje. Os ditos "pensadores autoritários" viram esse fenômeno com acuidade ímpar; alguns militares, na década de 30 , chegaram a visăo semelhante. $\mathrm{Na}$ oposiçăo a uns e outros, os bem pensantes que vicram depois de 45 , quando o ditador Vargas foi deposto, fizeram questâo de combatera influência nefasta dos autoritáriosque reclamavam que o povodeveria ter consciência de seus direitos civis, c cuidaram de fazer que nenhuma das instituiçốes construídas no período de 30 a 45 para consolidar otriunfo do Estado sobre uma sociedade desorganizada fossem abaladas, especialmente no campo das relações de trabalho.

O liberalismo-desculpem a repetiçăo c a simplificação - nãoć um corpo acabado de doutrina; permite que se defendam suas conquistas no terrenopolíticoe dos direitos individuais (os direitos políticos) e se aceite, quando năo se peça a intervenção do Estado na cconomia. Nos dircitos civis pouco se toca, porque sāo supostos corolários dos dircitos políticos. OEstado "guardiñoda noite", como foi caricaturado durante algum tempo, eraexatamente isso: os optimates gozavam de suas liberdades e reclamavam do Estado, que controlavam pelo Governo, que cuidasse de defendê-los contra aqueles que ainda nảo podiam as. cender à fruiçăo delas $\mathrm{c}$ dos direitos civis $\mathrm{e}$ políticos. Isso para năo dizer das políticas que punham em prática para defender fatias do mercado, quando nẩo todo $\mathrm{cle}$, contra a concorrência estrangeira. O movimentode massas livre dos tentáculos doEsstado-nesse particular, o político c osocial se confundiam, pois as associaçöes não podem buscar sua legitimidade funcional no Estado sob pena de as liberdades e os direitos serem tidoscomo apropriados pelos burocratasque integravamoGoverno-contribuiu para que o resultadodessa intervençăo do Estadona vida economica e social tivesse resultados danosos para o gozo das liberdades civis e políticas por parte de quem nāopertencesse às coteries ou delas fosse dependente. Se até as tabacarias dependiam da burocracia francesa noSegundo Império, nem por isso a burocracia, aquela jibóia a que Marx se referia com muita propriedade, chegou a

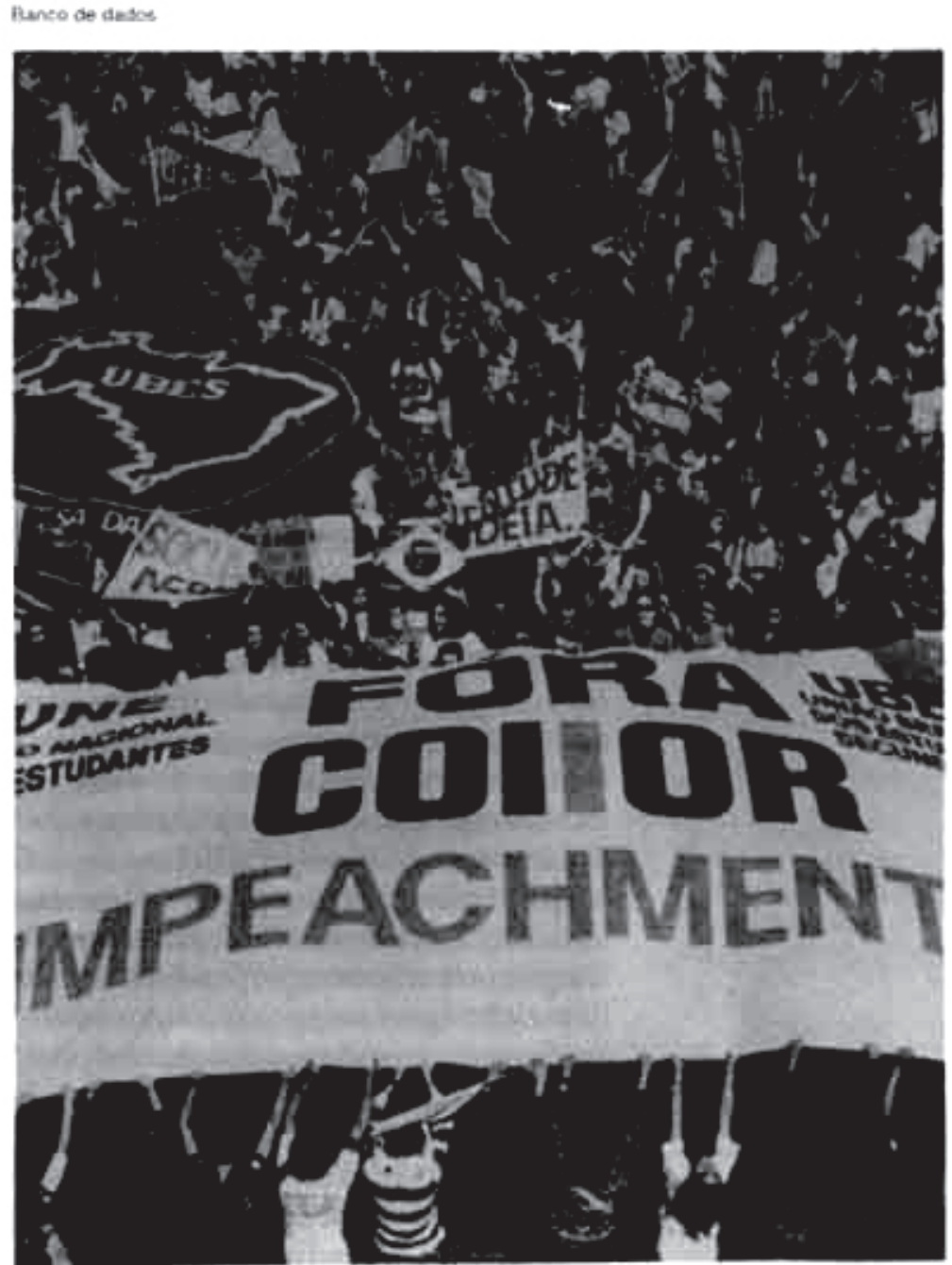


constituir-se num grupo social capaz de sufocar ou intermediar as reivindicaçóes dos despossuídos para enquadrá-las nos desíg. nios do Governo controlado pelos proprictários e seus dependentes, aglutinados pelas afinidades eletivas em diferentes gozos sociais da cultura. Nesse sentido, a matriz irracional da vida social, para lembrar as liçőes de Mannhcim, continuou "irracional" nosentido que the emprestava oautor de Ideologiae Utopia. Continuando irracional c livre, foi capaz, portanto, de provocar alteraçōes profundas nas relaçöes sociaise de poder na socicdade geral. No Brasil, ascoisas foram diferentesea irracionalidade da matriz irracional se perdeu por obra c graça dos autoritários, dos pensadores católicos e de quantos, após a queda de Vargas $\mathrm{cm} 45$, nada fizcram para modificar a legislaçâo sindical do Estado Novo, embora se dissessem defensores dos trabalhadores.

Ocerceamentoda organizaçāodos trabalhadores produziu efeitos mais profundos do que a Ciência Política moderna poderia supor - com certeza, apenas a Sociologia clássica poderia permitir se vissem as coisas mais longe. A legislação sindical (meiocorporativista, meiointervencionista, meio estatizante das relaçỏes sociais) cortou a possibilidade de as lutas sociais se travarem no terreno que the seria próprio, istoé, oda sociedade, $e$ as transferiu para $o$ do Estado, via Justiça do Trabalho e a umbilical ligaçãodos sindicatos ao Ministério do Trabalho. Nesse quadro social - sem referir-me aos demais, próprios de um país que até 1950 era rural e năo urbano-seria extremamente dificil encontrar dirigentes que desejassem levar oliberalismo-oreconhecimento e aceitaçáo normal das divergèncias, do conflito - à prática. Os mais "progressistas" poderiam imaginar transformaçóes via ilustraçîode quantos pudessem chegar à Universidade gratuita, mas nâo sabiam atender a reclamação de direitos sociais fora dos quadros muito estreitos da vida constitucional $\mathrm{e}$ política da época. Sobretudo, moviam-se nos limites impostos pela cosmovisáo preponderante numa sociedade que tinha muitode rural, especialmente pela concentraçúo populacional. Os liberais integravam gruposque se poderiam dizer urbanos nessi sociedade rural pelas práticas e pelos costumes; seu liberalismo manifestava-se na pertença a algumas sociedades secretas e na defesa do voto secreto, soluçẩo para tudo. Aomesmotempo,opondo-se aos que defendiam o voto a bico de pena, combatiam as pretensões dos "ruralistas" que descjavam o livre cambismo, a que os ditos liberais se opunham, pois eram mais urbanizados e mais ligados à indústria nascentc.

Por outro lado, o conflito social que enseja o enriquecimento das relaçōes sociais e cria o campo fértil em que florescem os princípios e as idéias liberais, esse nảo pôde desenvolver-se fora dos quadros das práticase dos gestos instituídos pelos optimates. $\mathrm{Na}$ realidade política dodia-a-dia, os liberais urbanos defendiam tarifasalfandegárias altas, o que assegurava à indústria posiçấo cômoda no mercado interno, e o movimento operário não teve, depois de 1930 , condiçôes de impor-se comosujeitode uma parte de sua história. Coarctado pelos "pelegos" que o Estado Novocriara, e depois conduzido pelos partidos de esquerda que adentraram os sindicatos e, neles, passaram a defender a manutençío do Imposto Sindical (quando nâo se prestando aos manejos de setores industriais), omovimento de massas náo foi capaz de criar as condiçôes políticas que forçassem os liberais urbanizados a sustentarem sua luta, nem, noterrenocconómico, fazercom que as lutas sindicais levassem à modernizaçâo tecnológica, que permitiria, associada às tarifas protecionistas, num complexo jogo de forças sociais, que houvesse um desenvolvimento industrial "livre", $\mathrm{em}$ que a matriz irracional da vida social predominasse e impusesse a concorrência, que nâo apenas permitiria a referida modernização tecnológica com a qual os proprietários continuariam usufruindo lucros, como ensejaria, peloconfrontodas forças sociais liberadas pela tecnologia e pelomercado, a participação efetiva do "grande número" na vida política. Nessas condiçöes, o movimento operário, apesar da aparência das grandes greves, continuou sendo, comose dizia na Argentina de antes de 30, “la gran y funeral canalla".

Nāo apenas a prisão da matriz irracional da vida social $\mathrm{cm}$ uma camisa-de-força estatal explica por que as idéias liberais sempre inscritas nas constituiçōes nâochegaram a traduzir-se em práticas. Para esse retardo, fatal para odesenvolvimento politicocomose viu depoisde 1964, contribuiu também o modo peculiar pelo qual se dera a formaçío do Brasil, a organização de sua "formaçióo social". Creioque se faz mister, para ajudar a compreender o problema da inexistência doliberalismo cnquanto mo- 
vimento de idéias e organizaçâo de práticas socias $\mathrm{c}$ politicas, rever algumas das construçöes teóricas que vimosalinhavando(eu inclusive) a propósitoda formaçăo do Estadobrasileiro, dadocomopatrimonialista em decorrència da herança portuguesa. Écomum, hoje $\mathrm{cm}$ dia, ouvirmos ou lermos objurgatórias contra o patrimonialismo português que se transplantou para o Estadobrasileiro, coethos católico que impediu a formação do capitalismo tal qual se desenvolveu em países protestantes. Acredito que se faz mister rever em parte esses conceitos, quando mais nâo scja porque o Es. tado português de hoje se adapta perfeitamente bem aos modelos europeus adiantados, e a vida social e económica portuguesa, $\mathrm{cmbora}$ sofrendo as consequềncias do "reinoda estupidez" que imperou durante séculos e dos 50 anos de governosilazaristacatólico, nảoć tão "corporativa" quantoa brasileira (pelo menos noque se refere aos naturais c aos curopeus de fora de Portugal).

Éprecisoqualificar os maleficios causadospelaéticacatólica aodescenvolvimento brasileiro, ou latino-americano como pretendemalguns. Sem desejarme aprofundar na discussāo econômico-teológica, caberia estabelecerque a posiçãoda Igreja Católica diante da atividade econômica se concentrou antes de Leảo XIII naquestảo do "justo preço" e na defesa, feita por algumas or dens religiosas, dos "pobres" por oposiçî̃o aos"ricos". Tomadas abstratamente, essas palavras prestam-se a diferentes interpretações; creio que se vistas em seu contexto histórico-social, a doutrina do "justo preço"(pós-revoluçîiocomercial do século XI) reclamava que os preços fossem fixados $\mathrm{em}$ função do status (em sentido muito amplo) dos compradores e não de um lucro, presumido abusivo, do vendedor. Ademais, a queståo nảose entenderá completamente se náo se levar em conta que ao lado da doutrina do "justo preço"-que alguns economistas modernos entendem querer significar nåo um preço relacionado com ostatus do comprador, mas sim com o incipiente jogode mercadoque começa a se manifestar -, desenvolvia-se a condenaçióo da usura, que era intrínseca, embora não formalmente ligada à questāo do que se poderia chamar de lucro numa economia ainda não plenamente regida pelo modode reproduçãoampliado. Todas essas doutrinas desenvolvidas noseio da Igreja Católica (inclusive a condenação dos "ricos", que nâo podi- am ser vistos apenas como aqueles endinheirados que ao morrer legavam para bispados e conventos e que náo seriam condenados por terem propriedades $\mathrm{e}$ moeda sonante, mas talvez por nảo praticarem a caridade comoensinava São Paulo...) frutificaram no instante em que a concorrência começava a se estabelecer e o dinheiro. gerando dinheiro, ensaiava os primeiros passos para substituir a noçâoprofundamente arraigada de que os bens produzidos encontravam correspondência nảo na moeda (correspondênciadevalor abstrata), masem outro bem igualmente produzido para o consumo. As doutrinas econômicas formuladas pela Igreja Católica nesse período não condenavam o "lucro", nem o fato de alguns serem socialmente mais distinguidos doque outros: cram contrárias à usura (prática de de finiçăo extremamente difícil, inclusive porque nessa discussảo se introduz. com bastante vigor a idéia de que o "tempo" em que odinheiro permanece fora das mâos de seu proprietário deve ser considerado como fator impeditivo de que ele aplique esse numerárioem outra atividade produtiva) c contra o fato de as novas formas de produçăoque se insinuavam naquele universo semifechadodesconhecerem a posiçíosocial das pessoas, ignorandoque antes de tudo eram "pessoas", e por tratí-las a todas como iguais, "monadas" que valiam pelotrabalhoque podiam fornecer.

Insistir em que essas doutrinas impediram a organizaçãode uma "formaçăo social moderna" no Brasil ć supor que as idcologias podem sobreviver tal qual, séculos depois, em meio social que nada tem a ver com aquele em que nasceram. Que as idéias podem adaptar-se, e as palavras e os gestos que persistem simbolizar coisas diferentes daquelas que thes deram origem, é fato corriqueiro na análise psicanalítica, ortodoxa ou não, e no cstudo das ideologias. Sucede, porém, que, mudadoo quadrosocial,osimbolizadoé diferente doque osímbolo exprime $\mathrm{cm}$ sua pureza semântica. Qucro com isso propor à discussảo que o ethos católico nấo se arraigou no Brasil a nâo serdepois da "Rerum Novarum" c com sentido bastante diferente da doutrina do "justo preço" do dombate à usura. Sc, hoje, 1993, repetindo oquese disse possivelmente nos anos 50, mas com certeza nos 60, sc condena a Igreja Católica pelo não-desenvolvimentode um ethos capitalista no Brasil, e em parte pela existência de um Estado patrimonialista, é porque se construiu uma 
nova ideologia destinada a mascarar coisas que os grupos dominantes (a meu ver năoos há dirigentes, no sentido de Gramsci) nảo desejam se tome conhecimento, muito menos se adquira consciência.

Qual a grande acusação que se faz ao ethos católico? A de que é por culpa dele que se recusa reconhecimento ao empreendedor de sucesso, àquele que enriquece na atividade produtiva; a de que é essa ética católica que condena o lucro e que faz o grande númerose voltar contra os empresá. rios. Deixemos de ladoo sistema financeiro, quando entăo a idéia de usura mereceria discussão à parte, embora năo de todoafastada doque pretendo colocar. Ora, oque se encontra nas encíclicas papais sobre os problemas sociais (portanto sobre a cconomia) é a insistência em que se leve em consideraçåo, no processo cconômico, a "pessoa humana". Tendo em conta que desde Leâo XIII se está diante da rápida construção do sistema de produçãode mercadorias, que se exprime fatalmente $\mathrm{cm}$ "dinheiroque produz maisdinheiro", poder-se-ia dizer que a doutrina econômica da Igreja Católica vêo processo de produçấo de mercadorias da perspectiva do "consumidor", que exige respeito a sua condiçăode "pessoa" e à seu stanusquandose defronta com o preço fixadopelo "produtor" à luz de suas necessidadesenquanto produtor num sistema "anárquico" $\mathrm{e} \mathrm{cm}$ que a mercadoria produzida deve transformar-se rapidamente em dinheiro (quanto mais, e mais depressa, melhor) para que a atividade produtiva prossiga nâo produzindobens para serem consumidos, mas apenas mercadorias.

Ora, as relaçöes de dependência que sempre marcaram a sociedade no Brasil imperial e mesmo durante boa parte da República (e poder-se-ia dizer até hoje em muitos lugares do país) levaram a que o grande número (agora considerado da perspectica sociológica estrita, náo mais política) tivesse daatividade coonòmica essa visãode "consumidor", embora a idéia de status, da certeza garantida da vida e do respeito de seus iguais e o desvelo dos superiores para com ele já nảo existisse, pois a história havia caminhadoalguns séculos. É importante ter esse dado em conta; da mesma maneira, há outrodado importante para compreender a formaçảo das idéias, ou das ideologias, comose quiser: ligado à terra, em contato estreito com a Natureza da qual retirava seu sustento e seus status, e que explorava como a escrava que o satis- fazia, ou alegrava, enquanto escravidão houve, osenhor rural (de que o grande númerodependia no espaço imenso dosertáo ou da terra mais perto dos centros ditos urbanos, a qual se amanhava e ameigava), tinha (e talvez ainda tenha) da Cidade e do que nela se produz a visão do "consumidor", tanto mais que a terra não a trabalhava ele com suas mảos, mas primeiro os escravos e depois os imigrantes ou os libertos. Em suma, o senhor rural nảo produzia, embora tivesse noçáo muito precisa de que era graças a "seu" esforço, plantando, que aquelesque ele dizia serem seus exploradores viviam - afinal, disso ele tinha plena consciência, de onde vinham as cambiais que permitiam a importação do que todos consumiam, ou os insumos de que se serviam os que habitavam as cidades e produziam mercadorias que ele comprava? A nảo extensảo social dosistema de produçâo de mercadorias permitiu que se criasse essa idéia de que o empresário industrial era explorador e náo merecia respeito, pois nảo produzia cambiais (e foi através do comerciante que a idéia da exploração atingiu o produtor industrial, e através dos empréstimos das casas comissárias que os futuros banqueiros se viram acusados de usurários), e foi essa resistência de estruturas sociais e mentais à racionalidade da produção de mercadorias que deu vida à "ideologia doconsumidor", que ou era produtor rural, ou trabalhador rural dele dependente, levandoa que ela permeasse a sociedade toda. Creio que seria de extrema importancia estudar comoa relaçâosenhor-escravocontribuiu para reforçar essa "ideologia do consumidor", considerando-se também que o "escravo" (depois dependente) se via c era tido apenas como consumidor, além de seu trabalho enquanto tal ser desprezado pelos senhores, que consideravam não poder exercer atividade económica porque ela era, no fundo, exploradora e por issomesmoindigna. Há um elemento moral (indig. noexpressa isso) de suma importância nessa postura antiempresarial, antiurbana, $\mathrm{c}$ creioque pesquisas aprofundadas acabarảo por comprovar oque enuncio apenas para discussio.

Para que as idćias liberais, importadas da Europa ou dos Estados Unidos, pouco importa, e retrabalhadas no Brasil nảo se transformassem em práticas e gestos com ampla base social, seria preciso ter em conta também que entre as elites dirigentes, os "senhores" (liberais ou não na postura ver- 
bal) c o grande número não se estabeleceram contatos sociais criadores. A grande massa do povo foi condenada ao isolamento na medida $\mathrm{cm}$ que era tida comodependente e executava otrabalho braçal próprio, até muito próximo na história, do escravo, do negro. Hoje, 1993, a situaçẫo nãoé muito diversa, apesar dos progressos realizados... Opreconceito contra o negroc onordestino - os que executam as tarefas pesadas e sujas - grassa como nunca, talvez menos gravemente do que antes porque agora ć consciente, expressando-se simbolicamente na Constituição, que assim reconhece que a sociedade brasileira não reúne os elementos para ser vista como uma sociedade liberal!

Ademais, ogrupoilustrado-expressão que melhor define os que se consideravam e ainda hoje se vêem comoliberais - sempre foi pequenodemais diante da grande massa da populaçăo, que estava à margem do processo político-social, mesmo depois que a República ampliou odireito de voto. A visão do mundo desse grupo ilustrado tinha muitode "racionalista", de anticlerical da Europa bem pensante do século XIX; ao mesmotempo, os interesses materiaisdesse grupo levavam seus integrantes a permitiremque a Igreja Católica, além de zelarpelas Santas Casas de Misericórdia, cuidasse de apascentar as almas, reduzindo a possibilidade de elas descobrirem que havia outro tipode relacionamento possível entre os que tinham e os que nảo tinham. Isso por um lado; por outro, dois fatores levavam a que o liberalismo náo se expandisse enquanto práticas e enquanto gestos: um deles era o fato de que os grupos ilustrados tinham dificuldade em transmitir suas idéias aogrande número por um fato meramente lingüistico: ouniversodopensamentoliberal era tảo complexoe tảo "europeu" que os ilustrados não tinham como traduzir as idéias-chave em palavras acessiveis a uma massa, se nâo analfabeta, pelo menos nảo acostumada ao tipo de abstraçâo mental que odiscursoliberal necessariamente exige, por não ser simplificador das coisas. $O$ outro fator era que ogrande númeroera suficientemente grande no conjunto da sociedade para impor, pelo princípio da comunicabilidade, parte de sua visâo concreta do mundo aos dominantes que pretendiam pensar abstratamente. Esse problema, que estudo mais detalhadamente em "Nossa América, Indoamérica", nảose pode perder de vista, tanto mais quando sabemos que os fatos sociais se explicam pelo volu- me e densidade dos grupos sociais...

A esses fatores, há de se acrescentar outro, morfológico: a separaçâodos grupos sociais, a pequena falta de comunicação entre eles ao longo do território, a pouca riqueza de suas relações sociais e, até recentemente, a divisão do trabalho muito acanhada. Nãoé à toa que se escreveu $O P$ Poder Público e a Ordem Privada no Brasil: O Estado, o Poder Público de uma maneira geral, sendo obrigado pela extensāodo território a delegar tacitamente suas funçôes, especialmente seu Poder de Polícia e a fixação dos códigos de comportamento ao senhor local. Essa prática - tendemos a esquecer - persistiu na República, c os estudos sobre ocoronelismo, inclusive o urbano(a que se referia Maria Isaura Pereira de Queiroz), mostram que $\mathrm{cm}$ muitas partes ainda hoje é vigente. Nos espaços sociopolíticos das favelas, o novo "coronel" encontra como nutrir seu "curral eleitoral" (não quero, neste contexto, discutir comoo Estado muda rapidamente de configuraçăo quando a contravençăo e o tráficode drogas dominam amplos espaços sociais, quando não controlam organizaçōes sociais que, antes, ilustravam algo parecido com a matriz irracional da vida social). Ora, num quadro social em que o grande número contribui para reduzir o universo de pensamento do grupo ilustrado, $\mathrm{cm}$ que as relaçōes entre os dominantes cos dominados nảosâocriadoras, cada qual conservando a "sua" cultura; em que o ideário (se assim se pode chamar) liberal nảo tem como se expressar no universo de discurso do grande número, e $\mathrm{cm}$ que osenhor privadoé o representante do Poder Público, comose pretenderá desenvolver oliberalismo no Brasil? Omovimentooperário, as lutas sociais inspiradas por doutrinas igualmente importadas e que aqui passaram pelas mesmas vicissitudes do liberalismo e do próprio conservantismo, esse é um capítuloà parte.

Não sei se respondi à questâo de saber se há liberalismo no Brasil. Cuidei, mais do que de esmiuçar o pensamento dos que se julgavam liberais, de sugerir pontos de pesquisa para compreender por que essa doutrina, ou conjunto de principios sociais, políticos e econômicos, nāo conseguiu se firmar no Brasil, criando necessariamente a disjuntiva entre o estatismo que preside as relações econômicas e sociais desde 1930 (ou seria de antes?) e o movimento reivindicatório revolucionário, que por esse mesmoestatismo está informado. 